\title{
Associations Between Positive and Negative Affect and 12-Month Physical Disorders in a National Sample
}

\author{
Eric B. Weiser
}

Published online: 10 January 2012

(C) Springer Science+Business Media, LLC 2012

\begin{abstract}
Associations between positive and negative affect and a range of 12-month physical disorders were investigated in the Midlife Development in the United States Survey, a nationally representative sample of 3,032 adults ages 25-74. These associations were examined, controlling for relevant sociodemographic and psychiatric covariates. High positive affect was associated with decreased risk of physical disorders, whereas high negative affect was associated with increased risk. However, associations between positive affect and physical disorders were partially attenuated following adjustment for concurrent negative affect. Additionally, high affect balance was associated with decreased risk of physical disorders before and after adjustments. These findings underscore the relevance of affective disposition in health status, suggesting that both positive and negative affect may serve as viable health risk parameters.
\end{abstract}

Keywords Affect - Positive affect - Negative affect . MIDUS · Physical disorders

\section{Introduction}

Scientific interest in the relationship between psychological factors and physical health has been longstanding. Of these factors, individual differences in the experience and expression of various distressing emotional states-i.e., anger/hostility, depression, anxiety, and cynicism-are routinely discussed and have been found to be associated

E. B. Weiser $(\square)$

Curry College, 1071 Blue Hill Avenue, Milton, MA 02186, USA

e-mail: eweiser@curry.edu with numerous adverse health conditions, including coronary heart disease (Kubzansky \& Kawachi, 2000; Suls \& Bunde, 2005), high blood pressure (Jorgensen, Johnson, Kolodziej, \& Schreer, 1996; Patten et al., 2009; Yan et al., 2003), asthma (Huovinen, Kaprio, \& Koskenvuo, 2001; Lehrer, Isenberg, \& Hochron, 1993; Loerbroks, Apfelbacher, Thayer, Debling, \& Sturmer, 2009), stroke (Colantonio, Kasl, \& Ostfeld, 1992; Everson, Roberts, Goldberg, \& Kaplan, 1998), and diabetes (Anderson, Freedland, Clouse, \& Lustman, 2001; Lustman, Frank, \& McGill, 1991). However, the role and importance of positive emotions in health is less clear, although emerging evidence suggests that these emotions may serve as a protective factor against illnesses and mortality (Fredrickson, 1998; Pressman \& Cohen, 2005; Richman et al., 2005). Thus, the primary objective of this study was to explore this more extensively individual differences in both negative and positive emotional states and their associations with a range of physical disorders.

One of the ways in which negative and positive emotional states have been conceptualized is in terms of negative affect and positive affect. Negative affect is characterized as a "mood-dispositional dimension" (Watson \& Clark, 1984, p. 465) reflecting a pervasive tendency to experience a constellation of aversive mood states such as anxiety, depression, fear, disgust, and hostility (Watson \& Clark, 1984; Watson, Clark, \& Carey, 1988; Watson, Clark, \& Tellegen, 1988). Individuals high in negative affect experience distress, discomfort, and dissatisfaction across a wide range of situations, whereas those low in negative affect are more calm, content, and secure and satisfied with themselves (Watson \& Clark, 1984; Watson, Clark, \& Carey, 1988). In support of this conceptualization, studies have consistently demonstrated that anger/hostility, anxiety, and depression overlap substantially and that each loads appreciably on a single factor 
(e.g., Clark \& Watson, 1991; Costa \& McCrae, 1992; Diener \& Emmons, 1985; Raynor, Pogue-Geile, Kamarck, McCafferty, \& Mannuck, 2002; Smith \& Frohm, 1985; Watson Kotov, \& Gamez, 2006).

As with negative affect, positive affect has been characterized as a dimensional attribute, reflecting general well-being, enthusiasm, energy, and high activity. At one extreme, high positive affect refers to the general tendency to experience high energy, mental alertness, joy, interest, and pleasurable engagement with the environment, as contrasted with a low state of positive affect, a state characterized by lethargy, fatigue, and sadness (Watson \& Clark, 1984; Watson, Clark, \& Carey, 1988). Research indicates that positive affect and negative affect are orthogonal constructs, in that positive affect is neither simply the opposite nor the absence of negative affect, and that individuals are capable of experiencing high or low levels of both dimensions across time (Diener \& Emmons, 1985; Watson, Clark, \& Tellegen, 1988). Separate neural networks appear to regulate positive and negative emotions, with dopamine metabolism associated with positive affect and serotonin associated with negative affect (Burgdorf \& Panksepp, 2006; Depue, Luciana, Arbisisi, Collins, \& Leon, 1994; Hamer, 1996), supporting the notion that the two kinds of affect are independent of one another.

Studies investigating the relationship between affect and health conditions have traditionally considered an individual's score on one affect dimension at a time while disregarding his or her position on the other. Because these two affect dimensions are independent, and because they reflect degrees of well-being flowing in opposite directions, it is presumable, for example, that one who experiences high positive affect and low negative affect would experience a predominance of positive emotions, whereas one who experiences low positive affect and high negative affect would experience a preponderance of negative emotions (Bradburn, 1969). In addition, individuals experiencing high levels of both positive and negative affect, or low levels of both, likely would experience neither a preponderance of positive nor negative emotions (i.e., their level of affect would be "balanced"). This assertion implies that one's general affective disposition is influenced largely by the interdependence of positive and negative affect. Subsequently, affect balance between positive and negative affect was determined in this study as a means to pragmatically conceptualize one's global affective disposition and level of emotional well-being.

As most of the previous work examining the relationship between psychological factors and illness has focused primarily on negative emotions, the importance of positive emotions in health outcomes is unclear. Additionally, most work has focused chiefly on single illness endpoints, such as coronary heart disease, and has failed to investigate the extent to which individual differences in global emotional states are associated with a broader range of physical disorders. The current investigation sought to overcome these limitations by drawing on a large and nationally representative study, the Midlife Development in the United States Survey (MIDUS), that included psychometrically sound measures of positive and negative affect, as well as measures of a wide range of 12-month physical disorders. Specifically, this study addressed three key questions: (1) what are the associations between positive and negative affect and a range of adverse health conditions; (2) to what extent is the balance between positive and negative affect associated with these conditions; and (3) to what extent will these associations, if present, persist after adjusting for potentially confounding sociodemographic covariates and psychiatric symptomatology?

From a public health standpoint, research in this domain is crucial because of its potential to contribute important information regarding the components and mechanisms that mediate the broader link between psychology and health. To date, there are indications that positive and negative affect are related to unique biological processes, especially that of the immune system, that are known to influence health status (Herbert \& Cohen, 1993; Marshland, Cohen, Rabin, \& Manuck, 2001, 2006; Ryff et al., 2006). Additionally, positive and negative affect appear to be associated with differences in various psychosocial processes, such as social support and adaptive coping, empirically demonstrated to have health-protective characteristics (Steptoe, O'Donnell, Marmot, \& Wardle, 2008). As such, determining if and how individual differences in positive and negative affect are related to a wide range of health outcomes may inform the development of practical prevention and interventions strategies, as well as help identify whom to target for such programs.

\section{Method}

Sample

The MIDUS is a nationally representative telephone and postal survey of 3,032 individuals in the civilian adult population of the United States, conducted by the John D. and Catherine D. MacArthur Foundation on Successful Midlife Development between January 1995 and January 1996 (Brim et al., 2000). Despite the somewhat dated nature of the MIDUS data, it was essential for the purposes of this investigation to obtain a database that was sufficiently large and representative enough to permit a generalizable analysis of the connections between affective dispositions and health. It was also necessary that such a 
database consist of items constituting reliable and valid measures of positive and negative affect, as well as measures of self-reported health problems. The MIDUS was one of the few datasets available meeting these vital criteria and thus was employed in this study.

The general purpose of the MIDUS was to examine patterns, predictors, and consequences of midlife development in the realms of physical health, psychological well-being, and social responsibility. Respondents were drawn from a random-digit-dial sample of non-institutionalized, English-speaking adults, ages 25-74, selected from working telephone banks in the continental United States. Respondent information was obtained via the Midlife Development Inventory (MIDI) (Lachman \& Weaver, 1998) and consisted of a 30-minute telephone interview (70\% response rate), followed by completion of two mailed questionnaires $(86.8 \%$ response rated among those who completed the telephone interview) estimated to take an average of 2 hours to complete, resulting in an overall response rate of $60.8 \%$ (Brim et al., 2000). Approximately $49 \%$ of the respondents were male, and the average age in the sample was $47.06(\mathrm{SD}=13.12)$. The majority of the sample were Caucasian $(88 \%)$ and were well educated, with $29 \%$ having attained at least a Bachelor's degree. Additional details concerning the MIDUS survey design, field procedures, and sample representativeness are available elsewhere (Brim et al., 2000; Kessler, DuPont, Berglund, \& Wittchen, 1999).

\section{Measures}

\section{Positive and Negative Affect}

The positive and negative affect measures in the MIDUS each consisted of a list of six feeling states to which respondents indicated how frequently they felt the way described in the statement during the last 30 days. The 30-day response frame was used for both affect measures to capture more generalized affect, rather than transient mood states (Mroczek \& Kolarz, 1998). Responses were coded on a 5-point Likert scale as follows: $1=$ all of the time; $2=$ most of the time; $3=$ some of the time; $4=a$ little of the time; and $5=$ none of the time. Total scores for each scale could range from 6 to 30; in the present investigation, these responses were reverse-coded such that higher scores would indicate higher levels of positive and negative affect.

In epidemiological research investigating associations between potential risk factors and binary outcomes, a common strategy is to categorize levels of a risk factor or an outcome variable, if either is measured on a continuous scale, to aid in interpreting the effect of the risk factor on the outcome (Woodward, 2005). In previous epidemiological studies examining associations between personality variables and the presence or absence of a physical illnesses (e.g., cancer), the limited number of cases of illness has routinely necessitated categorizing scores on personality measures into groups of roughly equal size based on the respective score distributions in the study population (e.g., Loerbroks et al., 2009; Nakaya et al., 2003). In this manner, scores on both affect measures in this study were split into two groups of approximately equal size to optimize subsequent analyses. As neither natural nor clinically-based thresholds have been defined or are known to exist (Nabi, Kivimaki, De Vogli, Marmot, \& Singh-Mannoux, 2008), scores on the positive and negative affect scales were dichotomized by splitting the distribution of scores at the median in the study population. ${ }^{1}$ Accordingly, those whose scores fell at or above the median on either scale were designated as having "high" positive and negative affect, whereas those respondents whose scores fell below the median were designated as having "low" positive and negative affect.

The Affect Balance Scale was developed by Bradburn (1969) as a measure of global emotional well-being. In general terms, affect balance may be conceptualized as the extent to which one experiences an overall positive mood state, an overall negative mood state, or a more "balanced" mood state. Individuals high in affect balance are said to be in an overall positive mood state, whereas those low in affect balance would experience an overall negative mood state (MacIntosh, 1998). Affect balance scores were calculated by subtracting the negative affect score from the positive affect score and adding a constant of 24 to avoid negative values. In this manner, the affect balance scores range from 0 (lowest affect balance) to 48 (highest affect balance). Scores on affect balance were classified as either "high" or "low" based on a median split of these scores; scores at or above the median in each were considered to represent high affect balance, whereas those below the median were designated as representing low affect balance.

The items comprising the positive affect scale were as follows: During the past 30 days, how much of the time did you feel (a) "cheerful?", (b) "in good spirits?", (c) "extremely happy?", (d) "calm and peaceful?",

\footnotetext{
1 Although MacCallum, Zhang, Preacher, and Rucker (2002) argued convincingly against the practice of dichotomization of quantitative variables, these authors indicated that dichotomization may be justifiable when a distribution of continuous scores is highly skewed because such circumstances more clearly demarcate the presence of two natural groups of individuals. Scores on both the positive and negative affect indices were heavily skewed in MIDUS; hence, dichotomization of these variables was deemed an appropriate strategy.
} 
(e) "satisfied?", and (f) "full of life?". The items comprising the negative affect scale included the following: During the past 30 days, how much of the time did you feel (a) "so sad nothing could cheer you up?", (b) "nervous?", (c) "restless or fidgety?", (d) "hopeless?", (e) "that everything was an effort?", and (f) "worthless?". In developing the MIDUS positive and negative affect scales, items were adopted from a variety of well-known and valid instruments including the original Affect Balance Scale (Bradburn, 1969), General Well-Being Schedule (Fazio, 1977), Center for Epidemiological Studies Depression Scale (Radloff, 1977), University of Michigan's Composite International Diagnostic Interview (Kessler et al., 1994), Health Opinion Survey (MacMillan, 1957), and Manifest Anxiety Scale (Taylor, 1953). Cronbach's alphas were .87 and .91 for the positive and negative affectscales, respectively (Brim et al., 2000).

\section{Physical Disorders}

Within the MIDUS, the presence of 12-month physical disorders was assessed via a self-report measure in which respondents indicated if they had experienced or been treated for any of a series of health problems. These health problems included asthma, bronchitis, or emphysema (hereafter referred to as "asthma"); other lung problem; arthritis, rheumatism, or other bone or joint disease (hereafter referred to as "arthritis"); sciatica, lumbago, or recurring backache (hereafter referred to as "sciatica/ lumbago"); persistent skin trouble (e.g., eczema); thyroid disease; hay fever; recurring stomach trouble, indigestion, or diarrhea (hereafter referred to as "recurring stomach trouble"); urinary or bladder problems; high blood pressure; migraine headaches; diabetes or high blood sugar (hereafter referred to as "diabetes"); stroke; ulcer; hernia or rupture; multiple sclerosis, epilepsy, or other neurological disorders (hereafter referred to as "neurological disorder"); gall bladder trouble; constipation; and lupus or other autoimmune disorder (hereafter referred to as "autoimmune disorder"). Checklists such as this are both a practical and efficient method of data collection in large epidemiological studies and yield more complete and accurate reports about chronic conditions than do openended questions (Knight, Stewart-Brown, \& Fletcher, 2001). In addition, methodological research has demonstrated that self-reports in checklists show moderate to good concordance with objective medical records (Baker, Stabile, \& Deri, 2004; Bergmann, Byers, Freedman, \& Mokdad, 1998; Kriegsman, Penninx, van Eijk, Boeke, \& Deeg, 1996) and predict health care utilization, hospitalization, and mortality (Fan, Au, Heagerty, Deyo, McDonell, \& Fihn, 2002). Nevertheless, self-reports are obviously less accurate than physician diagnoses or medical exams; thus, some degree of caution should be exercised in interpreting studies that use self-reports to assess physical conditions.

\section{Sociodemographic and Psychiatric Covariates}

In addition to gender and age group $(25-34,35-49,50-64$, 65-75), sociodemographic measures included race (white vs. nonwhite), marital status (married, divorced/separated, widowed, never married), education (less than high school, high school or GED, some college, college graduate or higher), employment (employed vs. unemployed or looking for work), smoking status (current smoker, ex-smoker, never smoked), level of alcohol use (regular, moderate, never), and the amount of moderate exercise in both summer and winter (greater than once per week, once per week, at least once per month, less than once per month or never).

The 12-month prevalence of major depressive disorder (MDD), generalized anxiety disorder (GAD), panic attacks, and alcohol and drug abuse or dependence were assessed in the MIDUS using the World Health Organization (WHO) Composite International Diagnostic Interview (CIDI) Short-Form (CIDI-SF). The CIDI-SF is a diagnostic instrument designed for use by trained interviewers who do not have clinical experience. The CIDI-SF was derived from the longer CIDI (WHO, 1990), and it consists of subsets of screening questions developed to assess mental disorders based on DSM-III-R criteria (American Psychiatric Association, 1987). The CIDI-SF is a valid and reliable diagnostic interview and has good classification accuracy for MDD and GAD (93 and 99\%, respectively) (Kessler, Andrews, Mroczek, Ustun, \& Wittchen, 1998).

\section{Analytic Strategy}

Cross-tabulations were used to calculate 12-month prevalence rates for each physical disorder for respondents scoring high and low on the positive and negative affect measures. A series of hierarchical logistic regression analyses yielded odds ratios (ORs), quantifying the strength of associations between high and low positive affect and presence of each specific physical disorder, and high and low negative affect and presence of each physical disorder. In these analyses, respondents with low positive affect and low negative affect served as the respective reference categories. The ORs representing the associations between high positive and negative affect and high affect balance and each of the 12-month physical disorders are presented first without adjustment, and subsequently are also adjusted separately for concurrent positive or negative affect (model 1), sociodemographic covariates (model 2), comorbid DSM-III-R disorders (i.e., MDD, GAD, panic attacks, and substance abuse or dependence) (model 3), and 
concurrent positive or negative affect, sociodemographic characteristics, and DSM-III-R disorders (model 4). Further, an additional series of hierarchical logistic regression analyses yielded ORs indicating associations between high and low affect balance and each physical disorder; respondents with low affect balance served as the reference category. These ORs are also presented with and without adjustment, as above.

Owing to the cross-sectional nature of this study, both unadjusted and adjusted ORs were interpreted as measures of association without implying any causal influence. An OR of 1.0 indicates no association exists between the predictor (i.e., affect level) and the criterion (i.e., presence of a physical disorder). An OR less than 1.0 indicates a lower probability of a physical disorder associated with a predictor; an OR greater than 1.0 indicates a higher probability of a physical disorder associated with the predictor. Corresponding 95\% confidence intervals (CIs) are provided for all ORs. Two percentages are regarded as different if the $95 \% \mathrm{CI}$ of their OR does not include a 1.0 (Agresti \& Min, 2002).

\section{Results}

Of the original 3,032 respondents, 2991 (98.6\%) and 2973 (98.1\%) completed fully the positive affect and negative affect scales, respectively. Among the 2,991 respondents completing the positive affect scale, 1,636 scored in the high range and 1,355 scored in the low range; among the 2,973 respondents completing the negative affect scale, 1,375 scored in the high range, whereas 1,598 scored in the low range.

The distributions of sociodemographic and psychiatric covariates by high and low positive affect, high and low negative affect, and high and low affect balance are displayed in Table 1. Men were more likely to have high positive affect and high affect balance scores than were women, who were more likely than men to have high negative affect scores. Increasing age was associated with an increase in both high positive affect and high affect balance and with a decrease in high negative affect. Nonwhites, relative to whites, had slightly greater rates of high positive affect, high negative affect, and high affect balance. Respondents who were either married or widowed, relative to those who were divorced or separated or who had never married, exhibited higher rates of high positive affect and affect balance and low rates of high negative affect. Higher education levels were associated with higher positive affect, lower negative affect, and higher affect balance. Respondents who were unemployed or looking for work, relative to those who were employed, tended to have low rates positive affect and affect balance and high rates of negative affect. In addition, rates of high positive affect and high affect balance were more frequent among those who reported having never smoked nor drank, whereas rates of high negative affect occurred most frequently among current smokers and regular alcohol users. Further, increasing frequency of exercise in both summer and winter was associated with both higher positive affect and affect balance and lower negative affect; those who reported never exercising or exercising less than once per month had the lowest rates of positive affect and affect balance and the highest rates of negative affect. Finally, each of the four DSM diagnoses was associated with low positive affect, high negative affect, and low affect balance.

Crude and adjusted associations between high positive affect and 12-month physical disorders are displayed in Table 2. With the exception of stroke and neurological disorder, respondents with high positive affect were significantly less likely than respondents with low positive affect to report having experienced each physical disorder within the last 12-months. Next, a series of hierarchical regression models testing these associations were conducted controlling independently for concurrent negative affect (model 1), sociodemographic covariates (model 2), comorbid DSM-III-R disorders (model 3), and each of the preceding variables as a group (model 4). After adjusting for differences in negative affect, individuals with high positive affect were no longer less likely than respondents with low positive affect to report asthma, other lung problem, arthritis, urinary or bladder problems, migraine headaches, diabetes, hernia or rupture, and autoimmune disorder. Interestingly, with very few exceptions high positive affect was associated with decreased odds of most of the disorders when adjusting independently for sociodemographic covariates and comorbid DSM-III-R disorders; in both cases, these adjusted estimates were similar to the crude ORs. With all four covariates included in the final adjusted model, respondents with high positive affect were significantly less likely than those with low positive affect to report sciatica/lumbago, persistent skin trouble, thyroid disease, hay fever, recurring stomach problems, high blood pressure, ulcer, and gall bladder trouble. In this final model, the strongest associations were observed between high positive affect and reduced likelihood of thyroid disease (OR, 0.50; 95\% CI, 0.33-0.77), gall bladder trouble (OR, $0.51 ; 95 \% \mathrm{CI}, 0.27-0.94)$, and ulcer (OR, 0.51; 95\% CI, $0.32-0.80)$.

Table 3 illustrates the unadjusted and the four adjusted estimates of the associations of high negative affect with each 12-month physical disorder. Crude ORs indicated that individuals with high negative affect were significantly more likely than individuals with low negative affect to report having experienced each physical disorder within the last 
Table 1 Participants ( $N$ and \%) with high or low positive affect scores, high or low negative affect scores, and high or low affect balance scores as a function of sociodemographic and psychiatric characteristics

\begin{tabular}{|c|c|c|c|c|c|c|}
\hline \multirow[b]{2}{*}{ Characteristic } & \multicolumn{2}{|c|}{ Positive affect* } & \multicolumn{2}{|c|}{ Negative affect* } & \multicolumn{2}{|c|}{ Affect balance* } \\
\hline & High & Low & High & Low & High & Low \\
\hline$N$ & 1636 & 1355 & 1375 & 1598 & 1486 & 1458 \\
\hline \multicolumn{7}{|l|}{ Sex } \\
\hline Male & $831(57.1)$ & $624(42.9)$ & $613(42.2)$ & $838(57.8)$ & 769 (53.4) & $671(46.6)$ \\
\hline Female & $805(52.4)$ & 731 (47.6) & $762(50.1)$ & $760(49.9)$ & 717 (47.7) & $787(52.3)$ \\
\hline \multicolumn{7}{|l|}{ Age group } \\
\hline $25-34$ & $323(52.0)$ & $298(48.0)$ & $333(53.7)$ & $287(46.3)$ & 274 (44.6) & $341(55.4)$ \\
\hline $35-49$ & $568(50.4)$ & 559 (49.6) & $530(47.6)$ & $583(52.4)$ & $522(47.2)$ & $584(52.8)$ \\
\hline $50-64$ & $528(58.0)$ & $383(42.0)$ & $378(41.7)$ & $528(58.3)$ & 489 (54.6) & $406(45.4)$ \\
\hline $65-75$ & $217(65.4)$ & 115 (34.6) & $134(40.1)$ & $200(59.9)$ & $201(61.3)$ & $127(38.7)$ \\
\hline \multicolumn{7}{|l|}{ Race } \\
\hline White & $1384(54.2)$ & $1171(45.8)$ & $1159(45.7)$ & $1378(54.3)$ & $1258(50.0)$ & $1258(50.0)$ \\
\hline Nonwhite & 205 (58.6) & $145(41.4)$ & $176(50.3)$ & $174(49.7)$ & $187(54.5)$ & $156(45.5)$ \\
\hline \multicolumn{7}{|l|}{ Marital status } \\
\hline Married & $1097(57.3)$ & $818(42.7)$ & $821(43.0)$ & $1087(57.0)$ & $1008(53.4)$ & $880(46.6)$ \\
\hline Divorced/separated & $269(48.4)$ & 287 (51.6) & $293(53.5)$ & $255(46.5)$ & $239(43.9)$ & $306(56.1)$ \\
\hline Widowed & $106(61.3)$ & $67(38.7)$ & $78(45.1)$ & $95(54.9)$ & $96(56.8)$ & $73(43.2)$ \\
\hline Never married & $164(47.3)$ & $183(52.7)$ & $183(53.2)$ & $161(46.8)$ & $143(41.8)$ & $199(58.2)$ \\
\hline \multicolumn{7}{|l|}{ Education } \\
\hline$<$ High school & $146(50.9)$ & $141(49.1)$ & $156(55.1)$ & $127(44.9)$ & $128(46.2)$ & $149(53.8)$ \\
\hline High school/GED & $467(53.2)$ & $410(46.8)$ & $425(48.6)$ & $540(51.4)$ & $422(48.8)$ & $443(51.2)$ \\
\hline Some college & $502(53.9)$ & $429(46.1)$ & $439(47.1)$ & $493(52.9)$ & $463(50.3)$ & $548(49.7)$ \\
\hline College graduate or $>$ & $521(58.3)$ & $373(41.7)$ & $353(40.1)$ & $528(59.9)$ & $473(53.8)$ & $406(46.2)$ \\
\hline \multicolumn{7}{|l|}{ Unemployed/looking for work } \\
\hline Yes & $31(34.4)$ & $59(65.6)$ & $48(53.9)$ & $41(46.1)$ & $33(37.5)$ & $55(62.5)$ \\
\hline No & $1597(55.4)$ & $1285(44.6)$ & $1318(46.0)$ & $1547(54.0)$ & $1445(50.9)$ & $1392(49.1)$ \\
\hline \multicolumn{7}{|l|}{ Smoking status } \\
\hline Current smoker & $331(48.0)$ & $359(52.0)$ & $369(53.9)$ & $315(46.1)$ & $289(42.6)$ & $390(57.4)$ \\
\hline Ex-smoker & $504(55.4)$ & $406(44.6)$ & $411(45.4)$ & $495(54.6)$ & $461(51.5)$ & $434(48.5)$ \\
\hline Never smoked & $801(57.6)$ & $590(42.4)$ & $595(43.0)$ & $788(57.0)$ & $736(53.7)$ & $634(46.3)$ \\
\hline \multicolumn{7}{|l|}{ Alcohol use } \\
\hline Regular & $644(51.3)$ & $612(48.7)$ & $634(50.6)$ & $619(49.4)$ & $578(46.5)$ & $664(53.5)$ \\
\hline Moderate & $873(56.5)$ & $671(43.5)$ & $652(42.5)$ & $881(57.5)$ & $802(52.9)$ & $714(47.1)$ \\
\hline Never & $119(62.3)$ & $72(37.7)$ & $89(47.6)$ & $98(52.4)$ & $106(57.0)$ & $80(43.0)$ \\
\hline \multicolumn{7}{|l|}{ Moderate exercise (summer) } \\
\hline$>$ Once per week & $1043(58.7)$ & $734(41.3)$ & $770(43.6)$ & $997(56.4)$ & $959(54.6)$ & $796(45.4)$ \\
\hline Once per week & $334(49.9)$ & $336(50.1)$ & $331(49.4)$ & $339(50.6)$ & $299(45.4)$ & $360(54.6)$ \\
\hline At least once per month & $192(48.1)$ & $207(51.9)$ & $195(49.0)$ & $203(51.0)$ & $170(43.3)$ & $223(56.7)$ \\
\hline$<$ Once per month or never & $62(44.9)$ & $76(55.1)$ & $75(56.8)$ & $57(43.2)$ & $55(42.0)$ & $76(58.0)$ \\
\hline \multicolumn{7}{|l|}{ Moderate exercise (winter) } \\
\hline$>$ Once per week & $920(59.9)$ & $615(40.1)$ & $657(43.0)$ & $871(57.0)$ & $844(55.6)$ & $673(44.4)$ \\
\hline Once per week & $370(50.1)$ & $369(49.9)$ & $364(49.5)$ & $372(50.5)$ & $336(46.3)$ & $389(53.7)$ \\
\hline At least once per month & $262(49.6)$ & $266(50.4)$ & $256(48.6)$ & $271(51.4)$ & $225(43.2)$ & $296(56.8)$ \\
\hline$<$ Once per month or never & $79(43.6)$ & $102(56.4)$ & $96(54.9)$ & $79(45.1)$ & $76(43.7)$ & $98(56.3)$ \\
\hline \multicolumn{7}{|l|}{ Depression } \\
\hline No & $1543(59.9)$ & $1034(40.1)$ & $1051(40.9)$ & $1519(59.1)$ & $1416(55.7)$ & $1128(44.3)$ \\
\hline Yes & $93(22.5)$ & $321(77.5)$ & $324(80.4)$ & 79 (19.6) & $70(17.5)$ & $330(82.5)$ \\
\hline
\end{tabular}


Table 1 continued

\begin{tabular}{|c|c|c|c|c|c|c|}
\hline \multirow[b]{2}{*}{ Characteristic } & \multicolumn{2}{|c|}{ Positive affect* } & \multicolumn{2}{|c|}{ Negative affect* } & \multicolumn{2}{|c|}{ Affect balance* } \\
\hline & High & Low & High & Low & High & Low \\
\hline \multicolumn{7}{|l|}{ GAD } \\
\hline No & $1625(56.0)$ & $1277(44.0)$ & $1298(45.0)$ & $1589(55.0)$ & $1478(51.7)$ & $1380(48.3)$ \\
\hline Yes & $11(12.4)$ & $78(87.6)$ & $77(89.5)$ & $9(10.5)$ & $8(9.3)$ & $78(90.7)$ \\
\hline \multicolumn{7}{|l|}{ Panic attacks } \\
\hline No & $1595(57.2)$ & $1194(42.8)$ & $1202(43.4)$ & $1570(56.6)$ & $1456(53.1)$ & $1288(46.9)$ \\
\hline Yes & $41(20.3)$ & $161(79.7)$ & $173(86.1)$ & $28(13.9)$ & $40(15.0)$ & $170(85.0)$ \\
\hline \multicolumn{7}{|c|}{ Alcohol/substance abuse } \\
\hline No & $1410(57.7)$ & $1033(42.3)$ & $1037(42.7)$ & $1391(57.3)$ & $1296(54.0)$ & $1106(46.0)$ \\
\hline Yes & $196(39.8)$ & $296(60.2)$ & $314(64.0)$ & $177(36.0)$ & $162(33.2)$ & $326(66.8)$ \\
\hline
\end{tabular}

* For each scale, high and low scores were defined based on the median split

12-months, except for gall bladder trouble. After adjusting for concurrent positive affect (model 1) and comorbid DSM-III-R disorders (model 3), high negative affect was no longer associated with increased odds of thyroid disease, stroke, and autoimmune disorder. No change in this pattern was observed after adjusting for all covariates (model 4); in this latter model, the strongest associations emerged between high negative affect and increased risk for neurological disorder (OR, 3.07; 95\% CI, 1.53-6.13), hernia or rupture (OR, 2.60; 95\% CI, 1.54-4.39), and ulcer (OR, 2.36; 95\% CI, 1.47-3.81).

Table 4 shows the unadjusted and adjusted associations of high affect balance with each physical disorder. Without adjustment, respondents with high affect balance were significantly less likely compared to those with low affect balance to report each physical disorder except for stroke and autoimmune disorder. However, the crude associations between high affect balance and reduced likelihood of neurological disorder and gall bladder trouble no longer emerged after adjusting independently for sociodemographic covariates (model 1) and comorbid DSM-III-R (model 2). Further, high affect balance was no longer associated with decreased odds of asthma when adjusting for all covariates (model 3). Nevertheless, high affect balance emerged as a somewhat robust predictor of most of the physical disorders in model 3. In this latter model, the strongest associations were between high affect balance and decreased odds of ulcer (OR, 0.42; 95\% CI, 0.27-0.65), other lung problem (OR, 0.44; 95\% CI, 0.28-0.71), and thyroid disease (OR, 0.46; 95\% CI, $0.31-0.69)$.

\section{Discussion}

The objective of this study was to examine the associations of positive affect, negative affect, and affect balance with 12-month physical disorders in the MIDUS sample. In general, the most salient finding was that high negative affect was independently associated with an increased risk of a broad range of physical disorders, and these associations changed little after taking into account the effects of concurrent positive affect, sociodemographic covariates, and comorbid mental disorders. These findings are congruent with previous investigations examining the relationship between negative emotions in general and adverse health conditions (e.g., Friedman \& Booth-Kewley, 1987; Scheier \& Bridges, 1995; Suls \& Bunde, 2005). For example, in Friedman and Booth-Kewley's (1987) well-known metaanalysis, weak but consistent associations emerged between negative emotions and conditions such as coronary heart disease, asthma, ulcers, arthritis, and headaches. Further, the fundamental personality trait of neuroticism has been found to be associated with the occurrence of a variety of physical illnesses, including hypertension, cardiovascular disease, diabetes, and asthma (Goodwin \& Friedman, 2006; Goodwin, Cox, \& Clara, 2006; Loerbroks et al., 2009), as well as increased likelihood of mortality among those with cardiovascular health problems (Smith \& MacKenzie, 2006; Suls $\&$ Bunde, 2005). Some authors have reported that individuals high in negative affect or neuroticism are more likely to complain of symptoms and are more likely to seek treatment (Ten Have, Oldehinkel, Vollebergh, \& Ormel, 2006; Watson $\&$ Pennebaker, 1989). Nevertheless, when viewed in context of the extant literature, the overall pattern, consistency, and strength of the findings underscores the notion that the relationship between negative emotions and physical illnesses likely is more than artifactual. Chronic negative emotional states appear to be strongly linked to physical disorders and adverse health, and the results of this study support the status of negative affect in this capacity.

This study also found that both high positive affect and high affect balance were each associated with a decreased likelihood of a range of physical disorders. These results 
Table 2 Unadjusted and adjusted OR) and 95\% confidence intervals (95\% CI) of physical disorders (12-month prevalence) as a function of high and low positive affect in the MIDUS

\begin{tabular}{|c|c|c|c|c|c|c|c|}
\hline \multirow[b]{2}{*}{ Physical disorder } & \multicolumn{7}{|c|}{ Positive affect } \\
\hline & $\begin{array}{l}\text { High } \\
(N, \%)\end{array}$ & $\begin{array}{l}\text { Low* } \\
(N, \%)\end{array}$ & $\begin{array}{l}\text { Unadjusted OR } \\
(95 \% \mathrm{CI})\end{array}$ & $\begin{array}{l}\text { Adjusted OR } \\
(\text { model 1) } \\
(95 \% \mathrm{CI})\end{array}$ & $\begin{array}{l}\text { Adjusted OR } \\
(\text { model 2) } \\
(95 \% \text { CI })\end{array}$ & $\begin{array}{l}\text { Adjusted OR } \\
(\text { model 3) } \\
(95 \% \mathrm{CI})\end{array}$ & $\begin{array}{l}\text { Adjusted OR } \\
(\text { model } 4)^{d} \\
(95 \% \text { CI })\end{array}$ \\
\hline Asthma & $184(11.3)$ & $208(15.4)$ & $0.70(0.56-0.86)$ & $0.87(0.69-1.10)$ & $0.76(0.61-0.95)$ & $0.85(0.67-1.07)$ & $0.99(0.77-1.29)$ \\
\hline Other lung problem & $45(2.8)$ & $69(5.1)$ & $0.53(0.36-0.77)$ & $0.76(0.49-1.16)$ & $0.58(0.39-0.87)$ & $0.64(0.42-0.97)$ & $0.92(0.58-1.47)$ \\
\hline Arthritis & $286(17.6)$ & $309(23.0)$ & $0.72(0.60-0.86)$ & $0.83(0.68-1.01)$ & $0.61(0.50-0.75)$ & $0.77(0.64-0.94)$ & $0.81(0.64-1.01)$ \\
\hline Sciatica/lumbago & $254(15.7)$ & $360(26.7)$ & $0.51(0.43-0.61)$ & $0.63(0.52-0.77)$ & $0.51(0.42-0.61)$ & $0.59(0.48-0.71)$ & $0.67(0.54-0.83)$ \\
\hline $\begin{array}{l}\text { Persistent skin } \\
\text { trouble }\end{array}$ & $137(8.4)$ & $192(14.2)$ & $0.56(0.44-0.70)$ & $0.69(0.53-0.89)$ & $0.54(0.42-0.69)$ & $0.62(0.48-0.79)$ & $0.69(0.53-0.91)$ \\
\hline Thyroid disease & $52(3.2)$ & $81(6.0)$ & $0.52(0.36-0.74)$ & $0.57(0.38-0.84)$ & $0.47(0.32-0.68)$ & $0.53(0.37-0.77)$ & $0.50(0.33-0.77)$ \\
\hline Hay fever & $221(13.6)$ & $267(19.8)$ & $0.63(0.52-0.77)$ & $0.74(0.60-0.92)$ & $0.63(0.51-0.77)$ & $0.72(0.58-0.89)$ & $0.77(0.62-0.98)$ \\
\hline $\begin{array}{l}\text { Recurring stomach } \\
\text { troubles }\end{array}$ & $224(13.8)$ & $377(28.0)$ & $0.41(0.34-0.49)$ & $0.58(0.47-0.71)$ & $0.43(0.36-0.52)$ & $0.49(0.40-0.60)$ & $0.65(0.52-0.81)$ \\
\hline $\begin{array}{l}\text { Urinary or bladder } \\
\text { problems }\end{array}$ & $182(11.2)$ & $220(16.3)$ & $0.65(0.52-0.80)$ & $0.84(0.66-1.06)$ & $0.65(0.52-0.81)$ & $68(0.54-0.85)$ & $0.84(0.65-1.08)$ \\
\hline High blood pressure & $262(16.1)$ & $282(20.9)$ & $0.73(0.60-0.88)$ & $0.72(0.59-0.89)$ & $0.62(0.51-0.76)$ & $0.72(0.59-0.88)$ & $0.77(0.61-0.97)$ \\
\hline Migraine headaches & $125(7.7)$ & $188(13.9)$ & $0.51(0.41-0.65)$ & $0.79(0.61-1.03)$ & $0.58(0.45-0.73)$ & $0.71(0.55-0.93)$ & $1.01(0.75-1.36)$ \\
\hline Diabetes & $75(4.6)$ & $88(6.5)$ & $0.69(0.50-0.95)$ & $0.85(0.60-1.21)$ & $0.59(0.42-0.83)$ & $0.68(0.48-0.94)$ & $0.73(0.49-1.07)$ \\
\hline Stroke & $12(0.7)$ & $18(1.3)$ & $0.55(0.26-1.14)$ & $0.91(0.40-2.09)$ & $0.60(0.27-1.31)$ & $0.77(0.35-1.70)$ & $1.25(0.48-3.28)$ \\
\hline Ulcer & $35(2.1)$ & $93(6.9)$ & $0.30(0.20-0.44)$ & $0.45(0.29-0.69)$ & $0.32(0.21-0.49)$ & $0.34(0.22-0.51)$ & $0.51(0.32-0.80)$ \\
\hline Hernia or rupture & $42(2.6)$ & $55(4.1)$ & $0.62(0.41-0.94)$ & $0.98(0.62-1.54)$ & $0.59(0.38-0.91)$ & $0.65(0.42-1.00)$ & $0.94(0.57-1.54)$ \\
\hline $\begin{array}{l}\text { Neurological } \\
\text { disorder }\end{array}$ & $25(1.5)$ & $30(2.2)$ & $0.69(0.40-1.17)$ & $1.01(0.56-1.83)$ & $0.82(0.47-1.42)$ & $0.79(0.44-1.41)$ & $1.27(0.67-2.42)$ \\
\hline Gall bladder trouble & $23(1.4)$ & $47(3.5)$ & $0.40(0.24-0.66)$ & $0.44(0.25-0.78)$ & $0.44(0.26-0.75)$ & $0.47(0.28-0.81)$ & $0.51(0.27-0.94)$ \\
\hline Constipation & $73(4.5)$ & $120(8.9)$ & $0.48(0.36-0.65)$ & $0.69(0.49-0.96)$ & $0.55(0.40-0.76)$ & $0.53(0.39-0.74)$ & $0.77(0.54-1.10)$ \\
\hline $\begin{array}{l}\text { Autoimmune } \\
\text { disorder }\end{array}$ & $17(1.0)$ & $21(1.6)$ & $0.53(0.36-0.77)$ & $0.89(0.43-1.86)$ & $0.73(0.36-1.44)$ & $0.75(0.37-1.52)$ & $1.00(0.45-2.25)$ \\
\hline
\end{tabular}

Note. Values in bold represent significant odds ratios

The numbers in the first two columns represent the total number $(N)$ and percent $(\%)$ of respondents in each affect category (high and low) with the physical disorder

${ }^{\text {a }}$ Model 1 ORs adjusted for concurrent negative affect

b Model 2 ORs adjusted for gender, age group, race, marital status, education level, employment, smoking status, alcohol use, and amount of moderate exercise in both summer and winter

${ }^{c}$ Model 3 ORs adjusted for presence of DSM-III-R disorders (MDD, GAD, panic attacks, and substance abuse or dependence)

${ }^{d}$ Model 4 ORs adjusted for concurrent negative affect, gender, age group, race, marital status, education level, employment, smoking status, alcohol use, amount of moderate exercise in both summer and winter, and presence of DSM-III-R disorders (MDD, GAD, panic attacks, and substance abuse or dependence)

* Low positive affect constituted the reference category

support emerging evidence suggesting that positive affect may be a protective factor against illnesses (Fredrickson, 1998; Pressman \& Cohen, 2005; Richman et al., 2005). For example, positive affect, independent of negative affect, has been demonstrated to be inversely related to the risk of incident stroke (Ostir, Markides, Peek, \& Goodwin, 2001), 10-year incidence of coronary heart disease (Davidson, Mostofsky, \& Whang, 2010), mortality in medical in-patients (Scherer \& Hermann-Lingen, 2009), and mortality in diabetic patients (Moskowitz, Epel, \& Acree, 2008). These findings are also consistent with research demonstrating a positive relationship between optimism and favorable subjective health (Rasmussen \& Wallio, 2008; Rasmussen, Scheier, \& Greenhouse, 2009), although it should be noted that the optimism differs somewhat from positive affect in that the former refers more to favorable outcome expectancies (Scheier \& Carver, 1985). However, negative and positive affect were not identical in their respective associations with the physical disorders. Specifically, when considering concurrent negative affect as a possible confounder, several of the associations between positive affect and physical disorders no longer remained 
Table 3 Unadjusted and adjusted OR and 95\% confidence intervals (95\% CI) of physical disorders (12-month prevalence) as a function of high and low negative affect in the MIDUS

\begin{tabular}{|c|c|c|c|c|c|c|c|}
\hline \multirow[b]{2}{*}{ Medical condition } & \multicolumn{7}{|c|}{ Negative affect } \\
\hline & $\begin{array}{l}\text { High } \\
(N, \%)\end{array}$ & $\begin{array}{l}\text { Low* } \\
(N, \%)\end{array}$ & $\begin{array}{l}\text { Unadjusted OR } \\
(95 \% \mathrm{CI})\end{array}$ & $\begin{array}{l}\text { Adjusted OR } \\
(\text { model 1) } \\
(95 \% \mathrm{CI})\end{array}$ & $\begin{array}{l}\text { Adjusted OR } \\
(\text { model 2) } \\
(95 \% \text { CI })\end{array}$ & $\begin{array}{l}\text { Adjusted OR } \\
(\text { model 3) } \\
(95 \% \mathrm{CI})\end{array}$ & $\begin{array}{l}\text { Adjusted OR } \\
(\text { model } 4)^{d} \\
(95 \% \text { CI })\end{array}$ \\
\hline Asthma & $230(16.8)$ & $161(10.1)$ & $1.80(1.45-2.23)$ & $1.68(1.33-2.13)$ & $1.63(1.30-2.04)$ & $1.52(1.20-1.92)$ & $1.42(1.10-1.84)$ \\
\hline Other lung problem & $75(5.5)$ & $34(2.1)$ & $2.67(1.77-4.04)$ & $2.46(1.57-3.87)$ & $2.67(1.73-4.12)$ & $2.22(1.43-3.44)$ & $2.27(1.38-3.73)$ \\
\hline Arthritis & $325(23.8)$ & $272(17.1)$ & $1.51(1.26-1.81)$ & $1.40(1.15-1.71)$ & $1.72(1.40-2.10)$ & 1.47 (1.21-1.79) & $1.41(1.12-1.77)$ \\
\hline Sciatica/lumbago & $362(26.6)$ & $247(15.5)$ & $1.97(1.64-2.36)$ & $1.63(1.33-1.99)$ & $1.97(1.63-2.38)$ & $1.74(1.43-2.11)$ & $1.50(1.21-1.87)$ \\
\hline $\begin{array}{l}\text { Persistent skin } \\
\text { trouble }\end{array}$ & $195(14.2)$ & $130(8.2)$ & $1.87(1.48-2.36)$ & $1.58(1.22-2.04)$ & $1.88(1.47-2.40)$ & $1.66(1.29-2.13)$ & $1.45(1.10-1.91)$ \\
\hline Thyroid disease & $72(5.3)$ & $58(3.6)$ & $1.47(1.03-2.10)$ & $1.15(0.78-1.70)$ & $1.47(1.01-2.13)$ & $1.39(0.95-2.04)$ & $1.03(0.67-1.58)$ \\
\hline Hay fever & $274(20.0)$ & $212(13.3)$ & 1.63 (1.34-1.98) & $1.42(1.14-1.77)$ & $1.65(2.35-2.02)$ & 1.44 (1.17-1.78) & $1.33(1.05-1.68)$ \\
\hline $\begin{array}{l}\text { Recurring stomach } \\
\text { troubles }\end{array}$ & $393(28.7)$ & $198(12.4)$ & $2.83(2.35-3.43)$ & $2.27(1.84-2.79)$ & $2.65(2.18-3.23)$ & 2.41 (1.97-2.95) & $1.97(1.58-2.46)$ \\
\hline $\begin{array}{l}\text { Urinary or bladder } \\
\text { problems }\end{array}$ & $237(17.4)$ & $159(10.0)$ & $1.89(1.52-2.34)$ & $1.75(1.38-2.22)$ & $1.89(1.50-2.36)$ & $1.83(1.46-2.31)$ & $1.65(1.28-2.13)$ \\
\hline High blood pressure & $289(21.1)$ & $245(15.5)$ & $1.46(1.21-1.77)$ & $1.39(1.13-1.71)$ & $1.66(1.35-2.04)$ & $1.51(1.23-1.85)$ & $1.43(1.13-1.81)$ \\
\hline Migraine headaches & $221(16.1)$ & $88(5.5)$ & $3.29(2.54-4.25)$ & $2.95(2.22-3.91)$ & $2.98(2.28-3.89)$ & $2.43(1.84-3.21)$ & $2.30(1.70-3.12)$ \\
\hline Diabetes & $94(6.9)$ & $66(4.1)$ & $1.70(1.23-2.35)$ & $1.56(1.09-2.24)$ & $1.90(1.35-2.68)$ & $1.90(1.35-2.67)$ & $1.67(1.13-2.48)$ \\
\hline Stroke & $19(1.4)$ & $28(0.9)$ & $2.47(1.12-5.49)$ & $2.26(0.94-5.43)$ & $2.41(1.05-5.55)$ & $1.87(0.80-4.38)$ & $1.67(0.62-4.49)$ \\
\hline Ulcer & $92(6.7)$ & $32(2.0)$ & $3.50(2.33-5.28)$ & $2.51(1.61-3.91)$ & $3.27(2.14-5.00)$ & $3.22(2.09-4.96)$ & $2.36(1.47-3.81)$ \\
\hline Hernia or rupture & $63(4.6)$ & $31(1.9)$ & $2.43(1.57-3.75)$ & $2.46(1.52-3.98)$ & $2.60(1.63-4.12)$ & $2.55(1.61-4.05)$ & $2.60(1.54-4.39)$ \\
\hline $\begin{array}{l}\text { Neurological } \\
\text { disorder }\end{array}$ & $38(2.8)$ & $16(1.0)$ & $2.81(1.56-5.06)$ & $2.79(1.45-5.24)$ & $2.62(1.43-4.79)$ & $3.01(1.58-5.74)$ & $3.07(1.53-6.13)$ \\
\hline Gall bladder trouble & $35(2.6)$ & $28(1.8)$ & $1.46(0.89-2.42)$ & $1.05(0.60-1.82)$ & $1.30(0.76-2.20)$ & $1.07(0.61-1.88)$ & $0.72(0.39-1.35)$ \\
\hline Constipation & $132(9.6)$ & $58(3.6)$ & $2.82(2.05-3.87)$ & $2.38(1.69-3.37)$ & $2.45(1.76-3.41)$ & $2.61(1.87-3.66)$ & $2.09(1.44-3.03)$ \\
\hline $\begin{array}{l}\text { Autoimmune } \\
\text { disorder }\end{array}$ & $23(1.7)$ & $13(0.8)$ & $2.07(1.05-4.11)$ & $1.90(0.89-4.04)$ & $2.16(1.04-4.48)$ & $1.97(0.93-4.17)$ & $1.94(0.83-4.44)$ \\
\hline
\end{tabular}

Note. Values in bold represent significant odds ratios

The numbers in the first two columns represent the total number $(N)$ and percent $(\%)$ of respondents in each affect category (high and low) with the physical disorder

${ }^{a}$ Model 1 ORs adjusted for concurrent positive affect

b Model 2 ORs adjusted for gender, age group, race, marital status, education level, unemployment, smoking status, alcohol use, and amount of moderate exercise in both summer and winter

${ }^{c}$ Model 3 ORs adjusted for presence of DSM-III-R disorders (MDD, GAD, panic attacks, and substance abuse or dependence)

${ }^{d}$ Model 4 ORs adjusted for concurrent negative affect, gender, age group, race, marital status, education level, employment, smoking status, alcohol use, amount of moderate exercise in both summer and winter, and presence of DSM-III-R disorders (MDD, GAD, panic attacks, and substance abuse or dependence)

* Low negative affect constituted the reference category

statistically significant. This finding highlights the notion that positive affect is not simply the absence of negative affect (Diener \& Emmons, 1985; Watson, Clark, \& Tellegen, 1988); more pragmatically, it suggests that concurrent negative affect should be considered when examining positive affect and its association with medical and illness outcomes.

Although the mechanisms through which positive and negative affect are linked with physical disorders are unknown and are likely complex and reciprocal, several such mechanisms seem especially viable, albeit speculative. First, it is possible that high negative and positive affect each has a general and direct influence on the development of physical disorders via biological and physiological processes related to these emotions. For example, traditional models of stress and stress adaptation, particularly that of Selye (1976), suggest that the cumulative "wear and tear" associated with emotional distress may eventually trigger allostatic mechanisms that increase the risk of illness and disease. Indeed, allostatic changes associated with enduring hypothalamic-pituitary-adrenal axis activation and concomitant elevations in cortisol 
Table 4 Unadjusted and adjusted ORs and 95\% confidence intervals (95\% CI) of physical disorders (12-month prevalence) as a function of high and low affect balance in the MIDUS

\begin{tabular}{|c|c|c|c|c|c|c|}
\hline \multirow[b]{2}{*}{ Medical condition } & \multicolumn{6}{|c|}{ Affect balance } \\
\hline & $\begin{array}{l}\text { High } \\
(N, \%)\end{array}$ & $\begin{array}{l}\text { Low* } \\
(N, \%)\end{array}$ & $\begin{array}{l}\text { Unadjusted } \\
\text { OR }(95 \% \text { CI })\end{array}$ & $\begin{array}{l}\text { Adjusted OR } \\
(\text { model 1) } \\
(95 \% \mathrm{CI})\end{array}$ & $\begin{array}{l}\text { Adjusted OR } \\
(\text { model 2) } \\
(95 \% \mathrm{CI})\end{array}$ & $\begin{array}{l}\text { Adjusted OR } \\
(\text { model 3) } \\
(95 \% \text { CI })\end{array}$ \\
\hline Asthma & $157(10.6)$ & $231(15.9)$ & $0.63(0.50-0.78)$ & $0.70(0.55-0.87)$ & $0.75(0.59-0.95)$ & $0.79(0.62-1.00)$ \\
\hline Other lung problem & $30(2.0)$ & $78(5.4)$ & $0.36(0.24-0.56)$ & $0.38(0.24-0.59)$ & $0.44(0.28-0.68)$ & $0.44(0.28-0.71)$ \\
\hline Arthritis & $252(17.1)$ & $337(23.2)$ & $0.68(0.57-0.82)$ & $0.57(0.46-0.69)$ & $0.71(0.59-0.87)$ & $0.65(0.52-0.80)$ \\
\hline Sciatica/lumbago & $220(14.9)$ & $385(26.5)$ & $0.49(0.40-0.58)$ & $0.47(0.39-0.57)$ & $0.55(0.45-0.67)$ & $0.54(0.44-0.66)$ \\
\hline Persistent skin trouble & $117(7.9)$ & $205(14.1)$ & $0.52(0.41-0.67)$ & $0.51(0.40-0.65)$ & $0.58(0.45-0.75)$ & $0.57(0.44-0.74)$ \\
\hline Thyroid disease & $44(3.0)$ & $85(5.9)$ & $0.49(0.34-0.72)$ & $0.44(0.30-0.66)$ & $0.49(0.33-0.73)$ & $0.46(0.31-0.69)$ \\
\hline Hay fever & $192(13.0)$ & $290(20.0)$ & $0.60(0.49-0.73)$ & $0.59(0.48-0.73)$ & $0.68(0.55-0.84)$ & $0.66(0.53-0.82)$ \\
\hline Recurring stomach troubles & $195(13.2)$ & $393(27.1)$ & $0.41(0.34-0.49)$ & $0.43(0.35-0.53)$ & $0.50(0.40-0.61)$ & $0.51(0.42-0.63)$ \\
\hline Urinary or bladder problems & $152(10.3)$ & $240(16.6)$ & $0.58(0.47-0.72)$ & $0.56(0.45-0.71)$ & $0.59(0.47-0.74)$ & $0.58(0.45-0.74)$ \\
\hline High blood pressure & $236(16.0)$ & $293(20.2)$ & $0.75(0.62-0.91)$ & $0.63(0.51-0.78)$ & $0.73(0.60-0.89)$ & $0.66(0.53-0.82)$ \\
\hline Migraine headaches & $95(6.4)$ & $211(14.5)$ & $0.41(0.31-0.52)$ & $0.44(0.34-0.57)$ & $0.55(0.42-0.72)$ & $0.56(0.42-0.75)$ \\
\hline Diabetes & $67(4.5)$ & $91(6.3)$ & $0.71(0.51-0.98)$ & $0.56(0.40-0.80)$ & $0.67(0.48-0.95)$ & $0.58(0.40-0.83)$ \\
\hline Stroke & $11(0.7)$ & $16(1.1)$ & $0.67(0.31-1.46)$ & $0.68(.30-1.53)$ & $0.99(0.42-2.31)$ & $1.14(0.46-2.82)$ \\
\hline Ulcer & $32(2.2)$ & $91(6.3)$ & $0.33(0.22-0.50)$ & $0.36(0.24-0.55)$ & $0.39(0.25-0.59)$ & $0.42(0.27-0.65)$ \\
\hline Hernia or rupture & $35(2.4)$ & $57(3.9)$ & $0.59(0.39-0.91)$ & $0.53(0.34-0.83)$ & $0.60(0.38-0.94)$ & $0.55(0.35-0.89)$ \\
\hline Neurological disorder & $19(1.3)$ & $34(2.3)$ & $0.55(0.31-0.96)$ & $0.60(0.34-1.07)$ & $0.61(0.33-1.12)$ & $0.65(0.35-1.21)$ \\
\hline Gall bladder trouble & $23(1.6)$ & $40(2.7)$ & $0.56(0.33-0.94)$ & $0.60(0.35-1.03)$ & $0.70(0.40-1.24)$ & $0.78(0.43-1.42)$ \\
\hline Constipation & $58(3.9)$ & $130(9.0)$ & $0.42(0.30-0.57)$ & $0.47(0.34-0.65)$ & $0.45(0.32-0.64)$ & $0.49(0.35-0.70)$ \\
\hline Autoimmune disorder & $12(0.8)$ & $23(1.6)$ & $0.51(0.25-1.03)$ & $0.51(0.24-1.08)$ & $0.53(0.25-1.14)$ & $0.55(0.25-1.20)$ \\
\hline
\end{tabular}

Note. Values in bold represent significant odds ratios

The numbers in the first two columns represent the total number $(N)$ and percent $(\%)$ of respondents in each affect balance category (high and low) with the physical disorder

${ }^{a}$ Model 1 ORs adjusted for gender, age group, race, marital status, education level, employment, smoking status, alcohol use, and amount of moderate exercise in both summer and winter

b Model 2 ORs adjusted for presence of DSM-III-R disorders (MDD, GAD, panic attacks, and substance abuse or dependence)

${ }^{c}$ Model 3 odds ratios adjusted for gender, age group, race, marital status, education level, employment, smoking status, alcohol use, amount of moderate exercise in both summer and winter, and presence of DSM-III-R disorders (MDD, GAD, panic attacks, and substance abuse or dependence)

* Low affect balance constituted the reference category

secretion include detrimental immunological processes, such as immunosuppression or excessive levels of proinflammatory cytokines (e.g., IL-6) (Robles, Glaser, \& Kiecolt-Glaser, 2005), as well as increased risks of cardiovascular diseases (al'Absi \& Wittmers, 2003; Flipovsky, Ducimetaere, Eschwaege, Richard, Rosselin, \& Claude, 1996), diabetes (Korenblum et al., 2005; Roy, Roy, \& Brown, 1998), osteoporosis (Chiodini et al., 2007), peptic ulcers (Lechin et al., 1990), and autoimmune diseases (Straub et al., 2004). As negative affect is considered to subsume negative emotions, such as depression (Watson \& Clark, 1984; Watson, Clark, \& Carey, 1988; Watson, Clark, \& Tellegen, 1988), and increased secretion of cortisol is one of the best documented biological correlates of depression, it is perhaps not coincidental that the prevalence of the disorders mentioned previously is high among people with depression (Evans et al., 2005; Sherwood Brown, Varghese, \& McEwen, 2004).

Positive affect has also been directly linked to biological and physiological markers including enhanced parasympathetic modulation of heart rate (Bhattacharyya, Whitehead, Rakhit, \& Steptoe, 2008), as well as lower blood pressure, lower norepinephrine activity during stressful laboratory tasks, and lower post-awakening cortisol levels (Brummett, Boyle, Kuhn, Siegler, \& Williams, 2009). Further, positive emotional states in general are associated with enhanced immunological processes such as higher salivary sIgA antibody concentrations (Stone, Neale, Cox, Napoli, Vadimarsdottir, \& Kennedy-Moore, 1994), and individuals who experience positive emotions such as joy and happiness are more resistant to developing objectively 
verified colds following experimentally-induced rhinovirus infection (Cohen, Doyle, Turner, Alper, \& Skoner, 2003; Doyle, Gentile, \& Cohen, 2006).

Second, it is plausible that positive and negative affect have a less direct effect on health via health-related behaviors that mediate the link between affect and physical disorders. In this study, positive affect, negative affect, and affect balance each was marginally associated with smoking status, alcohol use, and amount of exercise, initially signaling that these factors may potentially mediate the observed associations. However, the associations between affect and physical disorders generally continued to remain significant after adjustment for these variables. Thus, the extent to which these variables may serve as potential mediators seems weak. Third, positive and negative affect may be differentially linked with risks of physical disorders through individual differences in the uses of various coping mechanisms in response to stress and other problems. For example, there appears to be a positive association between negative affect and drinking as a means of coping (Todd, Armeli, \& Tennen, 2009). Elsewhere, others have reported that positive affect is associated with greater social support, optimism, and adaptive coping responses, whereas negative affect is associated with negative relationships, pessimism, and avoidant coping (Steptoe et al., 2008). Other research suggests that positive affect may produce patterns of thought and behavior that are flexible, creative, and open to new information, and might therefore promote adaptive coping by increasing one's personal resources (Tugade, Fredrickson, \& Feldman Barrett, 2004).

Fourth, it may be possible that having a physical disorder leads to decreased levels of positive affect or increased levels of negative affect, owing mainly either to the pain, discomfort, or physical limitations concomitant to such disorders. Finally, as others have suggested that a shared genetic vulnerability to both neuroticism and physical disorders may account for the link between these variables as described above (Johnson \& Krueger, 2005), it is certainly plausible that such a variable may also account for the associations between affect and physical disorders. As well, the presence of a comorbid mental disorder may serve as a third variable contributing substantially to this relationships. However, given that the strength of associations between the variables in this study remained significant after adjusting for comorbid mental disorders, this interpretation seems less credible.

Several limitations should be noted when interpreting the findings of this study. First, the cross-sectional nature of this investigation precludes any determination concerning the temporal sequencing of affect and physical disorders. Thus, it cannot be determined if a cause-effect relationship exists between these variables. Second, information on chronic physical conditions were assessed somewhat superficially via a self-report checklist rather than by consulting medical records or by administering medical exams. As noted earlier, methodological research has shown generally good agreement between self-reported health problems in checklists and objective medical records (Baker et al., 2004; Bergmann et al., 1998; Kriegsman et al., 1996). However, this concordance is most likely to be true for health problems for which a patient's knowledge or awareness depends exclusively on being informed of its presence by a physician (e.g., high blood pressure) and less likely for medical conditions that are mainly symptom-based (e.g., arthritis, recurring stomach troubles). Nevertheless, many of the affect-illness associations persisted after adjusting for comorbid mental disorders known to be routinely associated with increased reporting of somatic symptoms, suggesting the degree of misclassification to be small. Third, although the measures of positive and negative affect used in this study have been demonstrated to possess adequate psychometric properties, both dimensions encompass numerous domains, some of which overlap (Watson \& Clark, 1984; Watson, Clark, \& Carey, 1988); as such, one can argue that these dimensions are inadequately represented by six-item scales. However, these scales served as robust, consistent, and independent predictors of a variety of medical conditions in this study, validating their ability to differentiate within a population. Fourth, several of the 12-month disorders assessed in the MIDUS lacked specificity in their diagnosis (e.g., asthma, bronchitis, or emphysema were grouped together) thereby potentially obscuring the nature of some associations. Fifth, a high percentage of the sample in this study was Caucasian (88\%), thereby potentially limiting the generalizability of the findings to other racial and ethnic backgrounds. Lastly, the MIDUS data was used due to its large sample size as it was representative enough to permit analysis of connections between affective dispositions and health. However, the data was collected over 15 years prior to this publication. Thus, although it would be likely relationships identified between variables would still be relevant, it is plausible that changes over the last 15 years in the population, individual lifestyles, and knowledge about mood disorders and health conditions would result in different findings if a current, similarly sized data base had been available for analysis.

Despite these limitations, the results of this study, which was based on a large and nationally representative sample, suggest a modest association exists between high positive affect and favorable health, whereas a strong and unequivocal linkage exists between negative affect and health problems. Further, high affect balance was significantly inversely associated with adverse health conditions, even after adjustment for potentially confounding variables. A major implication of these findings is that one's global affective disposition, together with known risk factors, is associated with health status and may potentially be a useful indicator of one's risk for a variety of adverse health conditions. From a clinical perspective, health education programs might emphasize the 
importance of individual differences in affective dispositions and encourage individuals to recognize how positive affect, negative affect, and their component emotions might potentially put them at risk for serious health problems and their associated functional impairments, loss of productivity, and decline in overall quality of life. Additionally, practical interventions aimed at augmenting positive affect and decreasing negative affect may be especially helpful in promoting favorable health. As Davidson et al. (2010) suggested, behavioral activation techniques, which traditionally are applied to the treatment of depression, seem promising in this regard. Behavioral activation, whereby engagement in positively reinforcing behaviors helping patients achieve desired goals is encouraged and engagement in behaviors interfering in achieving goals is discouraged, has been shown to be an effective means of treating depression (Dimidjian et al., 2006; Jacobson et al., 1996). By extension, interventions incorporating this theme may be beneficial for maintaining and improving physical health.

As the cost of health care continues to rise to unprecedented levels, every effort must be made, both personally and professionally, to consider the extent to which individual difference parameters are associated with health and longevity. Attention must also be directed toward empirically delineating the underlying mechanisms, particularly those that may be modifiable, that explain these associations. The results of this study indicate that positive and negative affect constitute crucial individual difference parameters worthy of further investigation.

\section{References}

Agresti, A., \& Min, Y. (2002). Unconditional small sample confidence intervals for the odds ratio. Biostatistics, 3, 379386.

al'Absi, M., \& Wittmers, L. E. (2003). Enhanced adrenocortical responses to stress in hypertension-prone men and women. Annals of Behavioral Medicine, 25, 25-33.

American Psychiatric Association. (1987). Diagnostic and statistical manual of mental disorders (3rd ed rev.). Washington, DC: Author.

Anderson, R. J., Freedland, K. E., Clouse, R. E., \& Lustman, P. J. (2001). The prevalence of comorbid depression in adults with diabetes: A meta-analysis. Diabetes Care, 24, 1069-1078.

Baker, M., Stabile, M., \& Deri, C. (2004). What do self-reported, objective, measures of health measure? Journal of Human Resources, 39, 1067-1093.

Bergmann, M. M., Byers, T., Freedman, D. S., \& Mokdad, A. (1998). Validity of self-reported diagnoses leading to hospitalization: A comparison of self-reports with hospital records in a prospective study of American adults. American Journal of Epidemiology, 147, 969-977.

Bhattacharyya, M. R., Whitehead, D. L., Rakhit, R., \& Steptoe, A. (2008). Depressed mood, positive affect, and heart rate variability in patients with suspected coronary artery disease. Psychosomatic Medicine, 70, 1020-1027.
Bradburn, N. M. (1969). The structure of psychological well-being. Chicago, IL: Aldine.

Brim, O.G., Baltes, P.B., Bumpass, L.L., Cleary, P.D., Featherman, D.L., Hazzard, W.R., et al. (2000). National survey of midlife development in the United States (MIDUS), 1995-1996. [Computer file]. Available from Inter-University Consortium for Political and Social Research [distributor]. Accessed December 15, 2009. Available at http://www.icpsr.umich.edu/icpsrweb/ ICPSR/studies $/ 2760$ ?archive $=I C P S R \& q=$ midus.

Brummett, B. H., Boyle, S. H., Kuhn, C. M., Siegler, I. C., \& Williams, R. B. (2009). Positive affect is associated with cardiovascular reactivity, norepinephrine level, and morning rise in salivary cortisol. Psychophysiology, 46, 862-869.

Burgdorf, J., \& Panksepp, J. (2006). The neurobiology of positive emotions. Neuroscience and Biobehavioral Review, 30, 173-187.

Chiodini, I., Mascia, M. L., Muscarella, S., Battista, C., Minisola, S., Arosio, M., et al. (2007). Subclinical hypercortisolism among outpatients referred for osteoporosis. Annals of Internal Medicine, 147, 541-548.

Clark, L. A., \& Watson, D. (1991). Tripartite model of anxiety and depression: Psychometric evidence and taxonomic implications. Journal of Abnormal Psychology, 100, 316-336.

Cohen, S., Doyle, W. J., Turner, R. B., Alper, C. M., \& Skoner, D. P. (2003). Emotional style and susceptibility to the common cold. Psychosomatic Medicine, 65, 652-657.

Colantonio, A., Kasl, S. V., \& Ostfeld, A. M. (1992). Depressive symptoms and other psychosocial factors as predictors of stroke in the elderly. American Journal of Epidemiology, 136, 884-894.

Costa, P. T., \& McCrae, R. R. (1992). Revised NEO Personality Inventory (NEO-PI-R) and NEO Five-Factor Inventory (NEOFFI): Professional manual. Odessa, FL: Psychological Assessment Resources.

Davidson, K. W., Mostofsky, E., \& Whang, W. (2010). Don't worry, be happy: Positive affect and reduced 10-year incident coronary heart disease: The Canadian Nova Scotia health study. European Heart Journal, 31, 1065-1070.

Depue, R., Luciana, M., Arbisisi, P., Collins, P., \& Leon, A. (1994). Dopamine and the structure of personality: Relation of agonistinduced dopamine activity to positive emotionality. Journal of Personality and Social Psychology, 67, 485-498.

Diener, E., \& Emmons, R. A. (1985). The independence of positive and negative affect. Journal of Personality and Social Psychology, 47, 1105-1117.

Dimidjian, S., Hollon, S. D., Dobson, K. S., Schmaling, K. B., Kohlenberg, R. J., Addis, M. E., et al. (2006). Randomized trial of behavioral activation, cognitive therapy, and antidepressant medication in the acute treatment of adults with major depression. Journal of Consulting and Clinical Psychology, 74, 658-670.

Doyle, W. J., Gentile, D. A., \& Cohen, S. (2006). Emotional style, nasal cytokines, and illness expression after experimental rhinovirus exposure. Brain, Behavior, and Immunity, 20, 175-181.

Evans, D. L., Charney, D. S., Lewis, L., Golden, R. N., Gorman, J. M., Krishnan, K. R. R., et al. (2005). Mood disorders in the medically ill: Scientific review and recommendations. Biological Psychiatry, 58, 175-189.

Everson, S. A., Roberts, R. E., Goldberg, D. E., \& Kaplan, G. A. (1998). Depressive symptoms and increased risk of stroke mortality over a 29-year period. Archives of Internal Medicine, $158,1133-1138$.

Fan, V. S., Au, D., Heagerty, P., Deyo, R. A., McDonell, M. B., \& Fihn, S. D. (2002). Validation of case-mix measures derived from self-reports of diagnoses and health. Journal of Clinical Epidemiology, 55, 371-380. 
Fazio, A. (1977). A concurrent validational study of the NCHS General Well-being Schedule. In vital and health statistics publication (Series 2, No. 73). Washington, DC: U.S. Government Printing Office.

Flipovsky, J., Ducimetaere, P., Eschwaege, E., Richard, J. L., Rosselin, G., \& Claude, J. R. (1996). The relationship of blood pressure with glucose, insulin, heart rate, free fatty acids and plasma cortisol levels according to degree of obesity in middleaged men. Journal of Hypertension, 14, 229-235.

Fredrickson, B. L. (1998). What good are positive emotions? Review of General Psychology, 2, 300-319.

Friedman, H. S., \& Booth-Kewley, S. (1987). The "disease-prone personality": A meta-analytic review of the construct. American Psychologist, 42, 539-555.

Goodwin, R. D., Cox, B. J., \& Clara, I. (2006). Neuroticism and physical disorders among adults in the community: Results from the National Comorbidity Survey. Journal of Behavioral Medicine, 29, 229-238.

Goodwin, R. D., \& Friedman, H. S. (2006). Health status and the fivefactor personality traits in a nationally representative sample. Journal of Health Psychology, 11, 643-654.

Hamer, D. H. (1996). The heritability of happiness. Nature Genetics, $14,125-126$

Herbert, T. B., \& Cohen, S. (1993). Stress and immunity in humans: A meta-analytic review. Psychosomatic Medicine, 55, 364-379.

Huovinen, E., Kaprio, J., \& Koskenvuo, M. (2001). Asthma in relation to personality traits, life satisfaction, and stress: A prospective study among 11,000 adults. Allergy, 56, 971-977.

Jacobson, N. S., Dobson, K. S., Truax, P. A., Addis, M. E., Koerner, K., Gollan, J. K., et al. (1996). A component analysis of cognitive-behavioral treatment for depression. Journal of Consulting and Clinical Psychology, 59, 547-557.

Johnson, W., \& Krueger, R. F. (2005). Predictors of physical health: Toward an integrated model of genetic and environmental antecedents. Journal of Gerontology, 60(B), 42-52.

Jorgensen, R. S., Johnson, B. T., Kolodziej, M. E., \& Schreer, G. E. (1996). Elevated blood pressure and personality: A meta-analytic review. Psychological Bulletin, 120, 293-320.

Kessler, R. C., Andrews, G., Mroczek, D., Ustun, B., \& Wittchen, H.U. (1998). The World Health Organization Composite International Diagnostic Interview Short-form (CIDI-SF). International Journal of Methods in Psychiatric Research, 7, 171-185.

Kessler, R. C., DuPont, R. L., Berglund, P., \& Wittchen, H.-U. (1999). Impairment in pure and comorbid generalized anxiety disorder and major depression at 12 months in two national surveys. American Journal of Psychiatry, 156, 1915-1923.

Kessler, R. C., McGonagle, K. A., Zhao, S., Nelson, C. B., Hughes, M., Eshleman, S., et al. (1994). Lifetime and 12-month prevalence of DSM-II-R psychiatric disorders in the United States. Archives of General Psychiatry, 51, 8-19.

Knight, M., Stewart-Brown, S., \& Fletcher, L. (2001). Estimating health needs: The impact of a checklist of conditions and quality of life measurement on health information derived from community surveys. Journal of Public Health Medicine, 23, 179-186.

Korenblum, W., Barthel, A., Lincinio, J., Wong, M.-L., Wolf, O. T., Kirschbaum, C., et al. (2005). Elevated cortisol levels and increased rates of diabetes and mood symptoms in Soviet Unionborn Jewish immigrants to Germany. Molecular Psychiatry, 10, 974-975.

Kriegsman, D. M., Penninx, B. W., van Eijk, J. T., Boeke, A. J., \& Deeg, D. J. (1996). Self-reports and general practitioner information on the presence of chronic diseases in community dwelling elderly: A study on the accuracy of patients' selfreports and on determinants of inaccuracy. Journal of Clinical Epidemiology, 49, 1407-1417.
Kubzansky, L. D., \& Kawachi, I. (2000). Going to the heart of the matter: Do negative emotions cause coronary heart disease? Journal of Psychosomatic Research, 28, 323-337.

Lachman, M. E., \& Weaver, S. L. (1998). The sense of control as a moderator of social class differences in health and well-being. Journal of Personality and Social Psychology, 74, 763-773.

Lechin, F., Van Der Dijs, B., Jara, H., Lechin, A. E., Cabren, A., Lechin, M. E., et al. (1990). Plasma neurotransmitters and cortisol in duodenal ulcer patients. Digestive Diseases and Science, 35, 1313-1319.

Lehrer, P. M., Isenberg, S., \& Hochron, S. M. (1993). Asthma and emotion: A review. Journal of Asthma, 30, 5-21.

Loerbroks, A., Apfelbacher, C. J., Thayer, J. F., Debling, D., \& Sturmer, T. (2009). Neuroticism, extraversion, stressful life events and asthma: A cohort study of middle adults. Allergy, 64, $1444-1450$.

Lustman, P. J., Frank, B. L., \& McGill, J. B. (1991). Relationship of personality characteristics to glucose regulation in adults with diabetes. Psychosomatic Medicine, 53, 305-312.

MacCallum, R. C., Zhang, S., Preacher, K., \& Rucker, D. D. (2002). On the practice of dichotomization of quantitative variables. Psychological Methods, 7, 19-40.

MacIntosh, R. (1998). A confirmatory factor analysis of the Affect Balance Scale in 38 nations: A researcher's note. Social Psychology Quarterly, 61, 83-95.

MacMillan, A. M. (1957). The Health Opinion Survey: Techniques for estimating prevalence of psychoneurotic and related types of disorder in communities. Psychological Reports, 3, 325-339.

Marshland, A. L., Cohen, S., Rabin, B. S., \& Manuck, S. B. (2001). Associations between stress, trait negative affect, acute immune reactivity, and antibody response to hepatitis $\mathrm{B}$ injection in healthy young adults. Health Psychology, 20, 4-11.

Marshland, A. L., Cohen, S., Rabin, B. S., \& Manuck, S. B. (2006). Trait positive affect and antibody response to hepatitis B vaccination. Brain, Behavior, and Immunity, 20, 261-269.

Moskowitz, J. T., Epel, E. S., \& Acree, M. (2008). Positive affect uniquely predicts lower risk of mortality in people with diabetes. Health Psychology, 27, 573-582.

Mroczek, D. K., \& Kolarz, C. M. (1998). The effect of age on positive and negative affect: A developmental perspective on happiness. Journal of Personality and Social Psychology, 75, 1333-1349.

Nabi, H., Kivimaki, M., De Vogli, R., Marmot, M. G., \& SinghMannoux, A. (2008). Positive and negative affect and risk of coronary heart disease: Whitehall II prospective study cohort. British Medical Journal, 337, 32-36.

Nakaya, N., Tsubono, Y., Hosokawa, T., Nishino, Y., Ohkubo, T., Hozawa, A., et al. (2003). Personality and the risk of cancer. Journal of the National Cancer Institute, 95, 799-805.

Ostir, G. V., Markides, K., Peek, K., \& Goodwin, J. (2001). The association between emotional well-being and the incidence of stroke in older adults. Psychosomatic Medicine, 63, 210-215.

Patten, S. B., Williams, J. V. A., Lavorato, D. H., Campbell, N. R. C., Eliasziw, M., \& Campbell, T. S. (2009). Major depression as a risk factor for high blood pressure: Epidemiologic evidence from a national longitudinal study. Psychosomatic Medicine, 71, 273-279.

Pressman, S. D., \& Cohen, S. (2005). Does positive affect influence health? Psychological Bulletin, 131, 925-971.

Radloff, L. S. (1977). The CES-D scales: A self-report depression scale for research in the general population. Applied Psychological Measurement, 1, 385-405.

Rasmussen, H. N., Scheier, M. F., \& Greenhouse, J. B. (2009). Optimism and physical health: A meta-analytic review. Annals of Behavioral Medicine, 37, 239-256.

Rasmussen, H. N., \& Wallio, S. C. (2008). The health benefits of optimism. In S. J. Lopez (Ed.), Positive psychology: Exploring 
the best in people (pp. 131-149). Westport, CT: Praeger Publishers.

Raynor, D. A., Pogue-Geile, M. F., Kamarck, T. W., McCafferty, J. M., \& Manuck, S. B. (2002). Covariation of psychosocial characteristics associated with cardiovascular disease: Genetic and environmental influences. Psychosomatic Medicine, 64, 191-203.

Richman, L. S., Kubzansky, L., Maselko, J., Kawachi, I., Choo, P., \& Bauer, M. (2005). Positive emotion and health: Going beyond the negative. Health Psychology, 24, 422-429.

Robles, T. F., Glaser, R., \& Kiecolt-Glaser, J. K. (2005). Out of balance: A new look at chronic stress, depression, and immunity. Current Directions in Psychological Science, 14, 111-115.

Roy, M. S., Roy, A., \& Brown, S. (1998). Increased urinary-free cortisol outputs in diabetic patients. Journal of Diabetes and Its Complications, 12, 24-27.

Ryff, C. D., Dienberg Love, G., Urry, H. L., Muller, D., Rosenkranz, M. A., Friedman, E. M., et al. (2006). Psychological well-being and ill-being: Do they have distinct or mirrored biological correlates? Psychotherapy and Psychosomatics, 75, 85-95.

Scheier, M. F., \& Bridges, M. W. (1995). Person variables and health: Personality predispositions and acute psychological states as shared determinants for disease. Psychosomatic Medicine, 57, 255-268.

Scheier, M. F., \& Carver, C. S. (1985). Optimism, coping, and health: Assessment and implications of generalized outcome expectancies. Health Psychology, 4, 219-247.

Scherer, M., \& Hermann-Lingen, C. (2009). Single item on positive affect is associated with 1-year survival in consecutive medical inpatients. General Hospital Psychiatry, 31, 8-13.

Selye, H. (1976). The stress of life (Rev. ed.). New York: McGrawHill.

Sherwood Brown, E., Varghese, F. P., \& McEwen, B. S. (2004). Association of depression with medical illness: Does cortisol play a role? Biological Psychiatry, 55, 1-9.

Smith, T. W., \& Frohm, K. D. (1985). What's so unhealthy about hostility? Construct validity and psychosocial correlates of the Cook and Medley Ho scales. Health Psychology, 4, 503-520.

Smith, T. W., \& MacKenzie, J. (2006). Personality and risk of physical illness. Annual Review of Clinical Psychology, 2, 435-467.

Steptoe, A., O’Donnell, K., Marmot, M., \& Wardle, J. (2008). Positive affect and psychosocial processes related to health. British Journal of Psychology, 99, 211-227.

Stone, A. A., Neale, J. M., Cox, D. S., Napoli, A., Vadimarsdottir, H., \& Kennedy-Moore, E. (1994). Daily events are associated with secretory immune response to an oral antigen in men. Health Psychology, 13, 440-446.

Straub, R. H., Weidler, C., Demmel, B., Herrmann, M., Kees, F., Schmidt, M., et al. (2004). Renal clearance and daily excretion of cortisol and adrenal androgens in patients with rheumatoid arthritis and systemic lupus erythematosus. Annals of the Rheumatic Diseases, 63, 961-968.

Suls, J., \& Bunde, J. (2005). Anger, anxiety, and depression as risk factors for cardiovascular disease: The problems and implications of overlapping affective dispositions. Psychological Bulletin, 131, 260-300.

Taylor, J. A. (1953). A personality scale of manifest anxiety. Journal of Abnormal and Social Psychology, 48, 285-290.

Ten Have, M., Oldehinkel, A., Vollebergh, W., \& Ormel, J. (2006). Does neuroticism explain variations in care service use for mental health problems in the general care population? Results from the Netherlands Mental Health Survey and Incidence Study (NEMESIS). Social Psychiatry and Psychiatric Epidemiology, 40, 425-431.

Todd, M., Armeli, S., \& Tennen, H. (2009). Interpersonal problems and negative mood as predictors of within-day time to drinking. Psychology of Addictive Behaviors, 23, 205-215.

Tugade, M. M., Fredrickson, B. L., \& Feldman Barrett, L. (2004). Psychological resilience and positive emotional granularity: Examining the benefits of positive emotions on coping and health. Journal of Personality, 72, 1161-1190.

Watson, D., \& Clark, L. A. (1984). Negative affectivity: The disposition to experience aversive emotional states. Psychological Bulletin, 96, 465-490.

Watson, D., Clark, L. A., \& Carey, G. (1988a). Positive and negative affectivity and their relation to anxiety and depressive disorders. Journal of Personality and Social Psychology, 97, 346-353.

Watson, D., Clark, L. A., \& Tellegen, A. (1988b). Development and validation of brief measure of positive and negative affect: The PANAS scale. Journal of Personality and Social Psychology, 54, 1063-1070.

Watson, D., Kotov, R., \& Gamez, W. (2006). Basic dimensions of temperament in relation to personality and psychopathology. In R. F. Krueger \& J. L. Tackett (Eds.), Personality and psychopathology. New York: Guilford.

Watson, D., \& Pennebaker, J. W. (1989). Health complaints, stress, and distress: Exploring the central role of negative affectivity. Psychological Review, 96, 234-264.

Woodward, M. (2005). Epidemiology: Study design and data analysis (2nd ed.). Boca Raton, FL: Chapman \& Hall/CRC.

World Health Organization. (1990). Composite International Diagnostic Interview (CIDI), version 1.0. Geneva: World Health Organization.

Yan, L. L., Liu, K., Matthews, K. A., Daviglus, M. L., Ferguson, T. F., \& Kiefe, C. I. (2003). Psychosocial factors and risk of hypertension: The Coronary Artery Risk Development in Young Adults (CARDIA Study. JAMA, 290, 2138-2148. 